\title{
Investigation on Effects of Schiff Base Complex to Hydroxyapatite Bioceramics
}

\author{
F. ÇALIŞKAN ${ }^{a, *}$, M. TUnA ${ }^{b}$, S.G. AKÇA ${ }^{c}$ \\ ${ }^{a}$ Sakarya University, Faculty of Technology, Department of Metallurgical and Materials Engineering, \\ 54187, Sakarya, Turkey \\ ${ }^{b}$ Sakarya University, Faculty of Arts and Sciences, Department of Chemistry, 54187, Sakarya, Turkey \\ ${ }^{c}$ Sakarya University, Faculty of Technology, Department of Manufacturing Engineering, 54187, Sakarya, Turkey
}

\begin{abstract}
The aim of this study was to evaluate the effects of Schiff base metal complex on the bio-compatible hydroxyapatite (HAp) ceramics. The reason for that was to produce, as the final product, the HAp in powder form, with extraordinary features like analgesic, antibacterial properties. This effect was provided by doping HAp powder with some Schiff base complexes during the powder extraction process. Schiff base complex used in the study was synthesized by condensation of primary amines with carbonyl compounds. The chemical structures of the synthesized compounds were confirmed by means of infrared (IR) spectroscopy and elemental analysis. Characterizations of the extracted HAp powders were carried out by using scanning electron microscopy for surface analysis and EDS analysis, X-ray diffraction for phase determination and grain size distribution. The bactericide effects of Zn SAE-added pure HAp were tested on E.Coli bacteria for the content range of 0-7 wt.\% of Zn-SAE. Consequently, bacterial activity of the calcium phosphate resulting powders was evolved by adding the Zn SAE Schiff base complex.
\end{abstract}

DOI: $10.12693 /$ APhysPolA.127.1393

PACS: 81.05.-t

\section{Introduction}

Calcium phosphate ceramics such as hydroxyapatite (HAp), tricalcium phosphate (TCP) have drawn special interest due to their biocompatibility. These bioceramics have many advantages, including their chemical similarity to bone minerals, protein adsorption properties, absorbability and high osteoconductive, nontoxic properties [1-2]. In the recent years, researchers on biomaterials have made various types of artificial bone from HAp, TCP, or BCP, which are being used in clinical applications [3]. Hydroxyapatite (HAp) which has a chemical formula of $\mathrm{Ca}_{10}\left(\mathrm{PO}_{4}\right)_{6}(\mathrm{OH})_{2}$, is one of the most important bioceramics. Hydroxyapatite was first used for periodontal lesion filling in 1981 and then its usage was extended to solid components, films for dental and bone implants [4]. The HAp is main inorganic component of human hard tissues, such as teeth and bones. The other attractive aspects of HAp are the ability of chemically interact and bond with the surrounding bone [5]. Synthesize of HAp powder is possible by two routes, that is, the production of synthetic powder and extraction of natural HA powder. Synthetic route includes different techniques such as direct precipitation, electrochemical deposition, hydrothermal synthesis and emulsion. The fabrication of the synthetic HA powder is a very complicated and sophisticated technique. Extraction of HAp from natural raw materials is inexpensive and is easier than the synthetic route [6].

*corresponding author; e-mail: fcaliskan@sakarya.edu.tr
Schiff metal base complexes have received increasing attention in recent year, due to their antimicrobial, anticancer, analgesic, anti-inflammatory and herbicidal applications. The main factor here is the existence of metal ions bonded to biologically active compounds which may enhance their activities. It is known that the existence of metal ions bonded to biologically active compounds in Schiff base complexes may enhance their activities [7-8]. The compounds carrying imine or azomethine $(-\mathrm{C}=\mathrm{N}-)$ functional group are known as Schiff bases. These were first synthesized by Hugo Schiff and have gained importance in medicinal and pharmaceutical fields, as anticancer, antimicrobial anti-inflammatory, analgesic, pesticidal agents [9-10]. Schiff bases are usually synthesized from condensation products of primary amines with carbonyl compounds and compounds having active carbonyl groups. Schiff base Cu complexes can represent antibacterial and anti proliferative activities, owing to the properties of the coordinate ligands alone. Various works revealed that Schiff base complex with Zn metal ions has antimicrobial and analgesic, anti-inflammatory effects [11-13].

We report herein the results of our studies on doping of hydroxyapatite bioactive ceramic powder, extracted from bovine bone, with the metal complexes of a Schiff base. The author expects to combine bioactive property of hydroxyapatite and antimicrobial and analgesic, antiinflammatory property of Schiff base Zn complexes. In this context, HAp bioactive ceramics with the anti bacterial and analgesic features was produced, for the use in bioceramic coatings and bone fillers, for filling of bone defects or voids (e.g. bone cancers). 


\section{Materials and method}

The present study has handled the fabrication of HAp bioactive ceramics with bioactivity in two steps; fabrication of Hydroxyapatite powder and synthesising of Schiff base metal complex, respectively.

Hydroxyapatite powder was produced from bovine bone (Meat and Fish Institution of Sakarya, Turkey), with the age of two years, used as the natural raw material, by thermal method, which is a fairly inexpensive technique. The HAp powder extraction method involves crushing into small pieces, boiling up at $100{ }^{\circ} \mathrm{C}$ for $3 \mathrm{~h}$ on a hot plate, burning up the remaining organic materials, heat treatment of the precursor in a furnace (Protherm PLF 130/9 model), and grinding by planetary milling. After the sieving, powder, with grain size of $30 \mu \mathrm{m}$, was obtained.

Analysis of $[\mathrm{Zn}(\mathrm{SAE})]_{3}(\mathrm{OH})_{3}$ complex gave $\mathrm{C}_{27} \mathrm{H}_{33} \mathrm{O}_{9} \mathrm{~N}_{3} \mathrm{Zn}_{3}$ (MW: $739 \mathrm{~g} / \mathrm{mol}$ ). While the calculated values (\%) were: $\mathrm{C}, 43.84 ; \mathrm{H}, 4.50 ; \mathrm{O}, 19.47$, $\mathrm{N}, 5.68, \mathrm{Zn}, 26.52$, the examined values were \%: C, 43.28; $\mathrm{H}, 4.51 ; \mathrm{N}, 5.15$. To prepare the Schiff base metal complex, salicylaldehide and 2-aminoetanol in $\mathrm{MeOH}(6 \mathrm{ml})$ were mixed to react in a glass balloon $(50 \mathrm{ml})$ for $3 \mathrm{~h}$ at room temperature. $\mathrm{Zn}(\mathrm{OAc})_{2} \cdot 2 \mathrm{H}_{2} \mathrm{O}(5.26 \mathrm{~g}, 12 \mathrm{mmol})$ was added in the mixture of reactants, and reaction was allowed to continue for $48 \mathrm{~h}$. Afterwards diethylether was added to the mixture, and mixing was carried for two more hours. Precipitant, looking like a crystalline material, was filtered under vacuum. The precipitant was washed first by a diethylether-MeOH mixture, and then by diethylether. Yellowish and crystalline-like product was obtained and the yield was $2.58 \mathrm{~g}$, or $57.0 \%$.

Hydroxyapatite powder and Schiff base metal complex powder were wet mixed by ball milling technique for $24 \mathrm{~h}$, using isopropyl alcohol as the milling medium. Following the mixing, rotary evaporator was used to homogeneously remove alcohol from the slurry at $90{ }^{\circ} \mathrm{C}$ for $1 \mathrm{~h}$. The powder was sieved through a 300 mesh sieve screen. The prepared powder was pressed into a steel die (12 mm in diameter) under pressure of $50 \mathrm{MPa}$. The compositions of the various batches are shown in Table. Particle size analysis of the used powders were performed on the Microtrack S3500, USA. The analysis revealed that the mean particle size was $1-2 \mu \mathrm{m}$.

Compositions and codes used in the TABLE study.

\begin{tabular}{c|c}
\hline \hline Code & Composition \\
\hline H & Pure HAp \\
H1 & HAp $+1 \%$ wt. Zn(SAE) 2 \\
H2 & HAp $+2 \%$ wt. Zn(SAE) 2 \\
H5 & HAp $+5 \%$ wt. Zn(SAE) 2 \\
H7 & HAp $+7 \%$ wt. Zn(SAE) 2
\end{tabular}

Scanning electron microscopy (SEM, JEOL, JSM$6700 \mathrm{~F}$, Japan) was performed to examine particle morphology of the fabricated HAp powder. EDS elemental analysis of both the HAp powder and Schiff base added

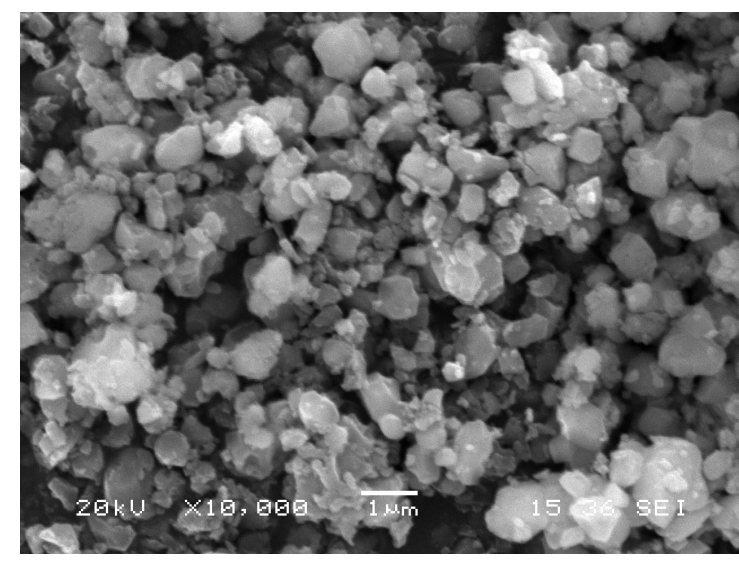

Fig. 1. SEM micrograph of HAp powders (with 5 wt.\% of Schiff base complex).

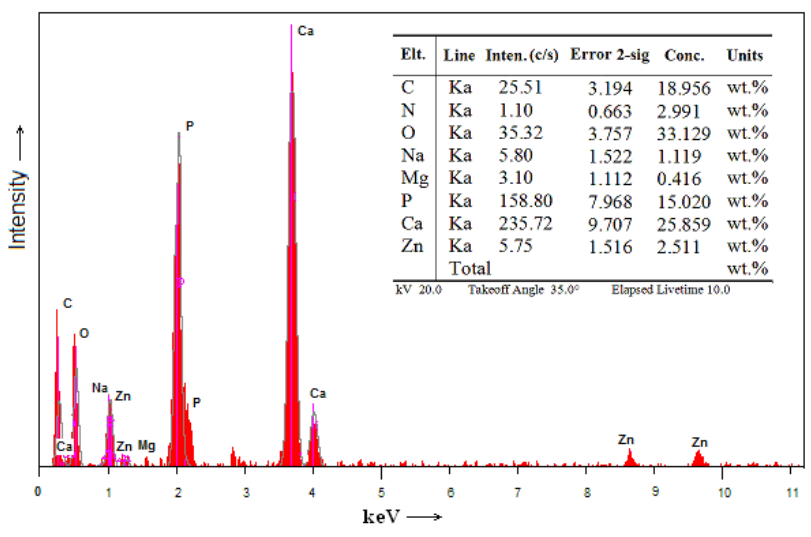

Fig. 2. EDS analysis for HAp powders with 5 wt. $\%$ of Schiff base complex.

powder were carried out to determine element content of the product. The HAp powder was analyzed using XRD (Rigaku Dimaks 2200) for identifying its phase compositions. FTIR (MIRacle ${ }^{T M}$ Single Reflection ATR) was used to reveal the presence of the Schiff base structure. In antibacterial tests, disks of pure HAp and HAp with various doses of Zn SAE were used to see toxic effect on bacteria and the inhibition of bacterial growth. Escherichia Coli DHS $\alpha$ strain, non-pathogenic, was used as a test organism (supplied by Sakarya University, Chemistry Laboratory, Sakarya, Turkey). E.Coli is a heterotrophic bacterium and can reproduce easily. Bacterial test kits (diffusion discs etc.) were purchased from Seçkin Medikal Company, Sakarya, Turkey. Naturally pure HAp, 0.1\%, $0.2 \%, 0.5 \%$ and $0.7 \% \mathrm{Zn}$ SAE-added HAp disks were used in disk diffusion method. After incubation, it is observed whether bacterial growths occurs or not. In another method, we have tried to observe bactericidal effect by colony counting in nutrient broth. Disk diffusion method was used for the antibacterial test. Sample taken from E.Coli culture was inoculated by spread plate method. The sterile disks (pure HAp, 0.1\%, 0.2\%, 0.5\% and $0.7 \%$ Zn SAE-added HAp) were placed on plate by applying the aseptic technique. Incubation was carried 
out for 48 hours. After that, the disks were spread from plates by applying aseptic techniques and incubated at $37^{\circ} \mathrm{C}$ for 48 hours.

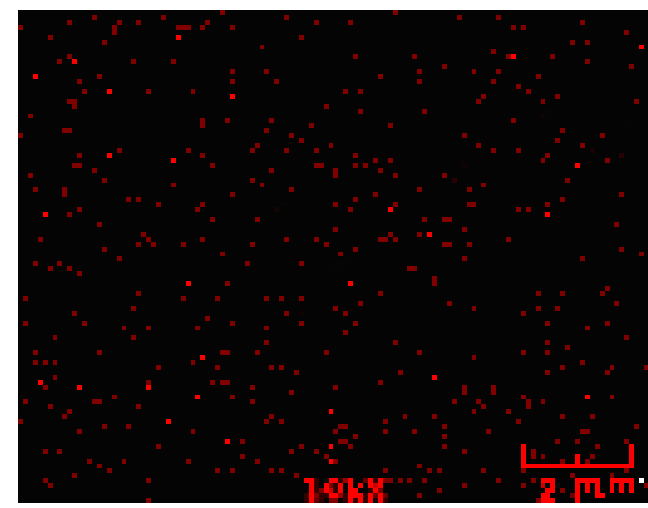

Fig. 3. EDS mapping of Fig. 1 for Zn distribution (red points).

\section{Results and discussion}

\subsection{Scanning electron microscopy and EDS elemental analysis of the hydroxyapatite powder}

As it is seen in Fig. 1, the produced hydroxyapatite powder has a narrow particle size distribution. Particle size of the powder is predominantly $<1 \mu \mathrm{m}$. Figure 1 shows SEM micrograph of HAp powder with 5 wt.\% of Schiff base complex. Figure 2 shows EDS analysis for the powders with 5 wt.\% Schiff base complex. It contained $\mathrm{Ca}, \mathrm{P}, \mathrm{Mg}, \mathrm{Na}, \mathrm{O}, \mathrm{C}, \mathrm{Zn}$. It is well known that elemental composition of the human bone tissue contains $\mathrm{Ca}, \mathrm{P}$, $\mathrm{Mg}, \mathrm{Na}, \mathrm{C}$, O elements but the $\mathrm{Zn}$ was added to gain analgesic and antibacterial properties. While $\mathrm{Ca}$ and $\mathrm{P}$ are the main elements, $\mathrm{Zn}$ provides antibacterial and analgesic effects. Uniform distribution of $\mathrm{Zn}$ is important because it shows whether a correct powder preparation process was performed. EDS mapping analysis can show distribution of any element in the microstructure. When looking at Fig. 3, Zn element can be seen virtually everywhere on Fig. 1. This means that Schiff base metal complex was homogeneously distributed in the hydroxyapatite powder.

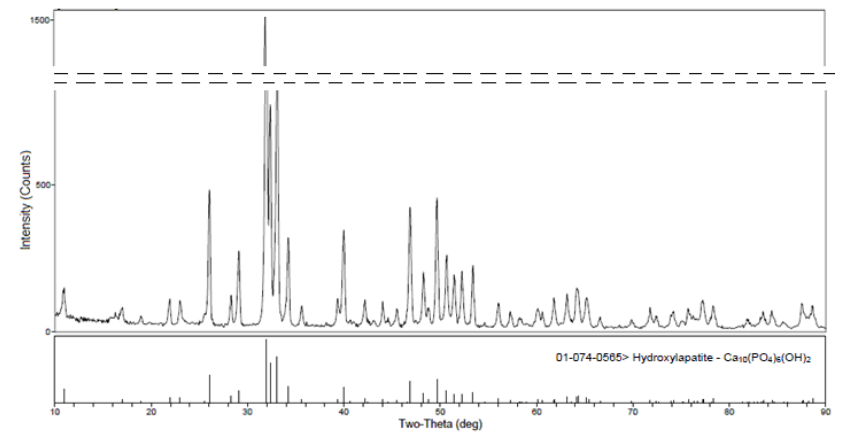

Fig. 4. X-ray analysis of HAp powders (with 2 wt.\% Schiff base complex).

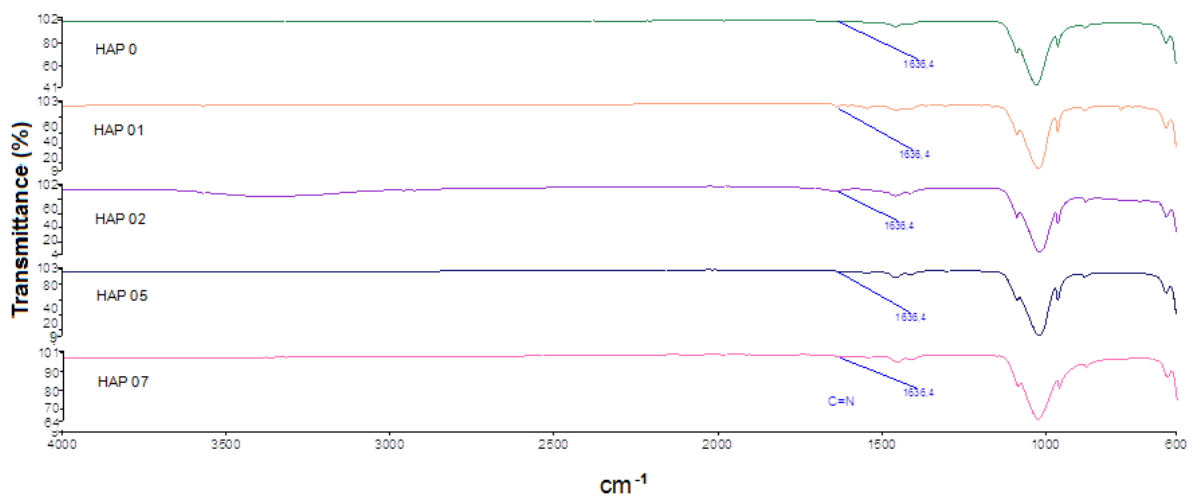

Fig. 5. FTIR spectra of pure HAp and HAp powders with various amount of Schiff base complex.

\subsection{X-ray analysis and IR spectroscopy of the prepared HAp powder}

Figure 4 shows the XRD pattern for the homemade produced hidroxyapatite. As can be clearly seen in Fig. 4, all characteristic peaks belong to hidroxyapatite phase $\left[\mathrm{Ca}_{10}\left(\mathrm{PO}_{4}\right)_{6}(\mathrm{OH})_{2}\right]$. That is to say, the production of monophase HAp powder was achieved during powder preparation, which was explained in Experimental section. Determination of Schiff base metal complexes via $\mathrm{X}$-ray analysis is difficult because of the low amount $(<5$ wt.\%) of Zn in Schiff base. Thus, Schiff base complex was examined by FTIR (Fig. 5). FTIR characterization for both the pure HAp and $[\mathrm{Zn}(\mathrm{SAE})]_{3}(\mathrm{OH})_{3}$-added
HAp sample was carried out to study the spectral characteristics, specific for the chemical bonding. The spectrum in Fig. 5 can be divided into three regions, with peaks having wave numbers around $3570 \mathrm{~cm}^{-1}, 1638$ $1450 \mathrm{~cm}^{-1}$ and $1085-960 \mathrm{~cm}^{-1} .3570 \mathrm{~cm}^{-1}$ peak can be attributed to $\mathrm{OH}$ groups in HAp molecules. In the same way, while the peaks at $1638-1450 \mathrm{~cm}^{-1}$ can be referred to double bonded oxygen, the peaks in the range of 1085 $960 \mathrm{~cm}^{-1}$ can be attributed to single bonded oxygen. The spectra of mixed HAp samples are similar to that of pure HAp, except for the peaks of $[\mathrm{Zn}(\mathrm{SAE})]_{3}(\mathrm{OH})_{3}$ complex. As shown in Fig. 5, an extra peak, belonging to $\mathrm{C}=\mathrm{N}$ bond in the mixed samples, was observed around 
$1636.4 \mathrm{~cm}^{-1}$. Weak peaks of $[\mathrm{Zn}(\mathrm{SAE})]_{3}(\mathrm{OH})_{3}$ complex in the spectrum may be due to low content of the addition in HAp.

\subsection{Antimicrobial effect of the resulting powder}

In antibacterial tests, HAp disks with different doses of Zn SAE and pure HAp were used to see toxic effect on bacteria and inhibition of bacterial growth. The antimicrobial effects of the specimens with and without $\mathrm{Zn}(\mathrm{SAE}) 2$ versus E.Coli are shown in Fig. 6. The main difference between the samples with and without $\mathrm{Zn}$ (SAE)2 is that the zinc ions released from HAp compacts have strong antimicrobial effects. Figure 6 a was the control sample for the HAp which had not any additive. The HAp with $\mathrm{Zn}(\mathrm{SAE}) 2$ samples had not the bacteria killer ability on contact, until the addition of amount of $5 \mathrm{wt} \% \mathrm{Zn}(\mathrm{SAE}) 2$ (Fig. $6 \mathrm{~b}$ and $6 \mathrm{c}$ ), because of the low concentration of $\mathrm{Zn}(\mathrm{SAE}) 2$. As obviously can be seen in Fig. 6, for the amount of $\geq 5$ wt.\% of $\mathrm{Zn}$ (SAE)2 (Fig. 6d), the HAp with $\mathrm{Zn}(\mathrm{SAE}) 2$ had started to exhibit the antibacterial effect of $\mathrm{Zn}(\mathrm{SAE}) 2$, due to adequate concentration. In addition, the bacterial free zone was apparently enhanced with the increase of $\mathrm{Zn}(\mathrm{SAE}) 2$ amount from Fig. $6 \mathrm{~b}$ to Fig. 6 d. However the zone was weak to show the antibacterial effect. In conclusion, Zn-added HAp disks were antibacterial and the most effective were the highest doses of Schiff base in HAp.

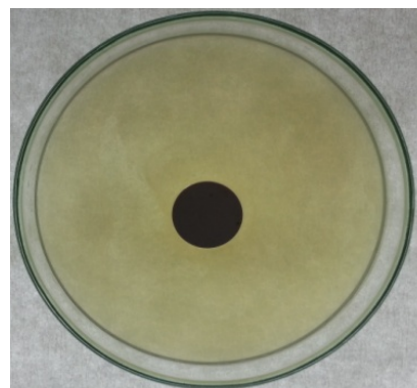

a) the control sample ( $\mathrm{Zn}(\mathrm{SAE}) 2$ free)

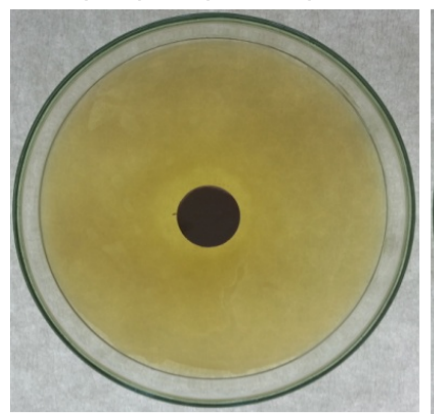

c) the Hap with $5 \% \mathrm{Zn}(\mathrm{SAE}) 2$

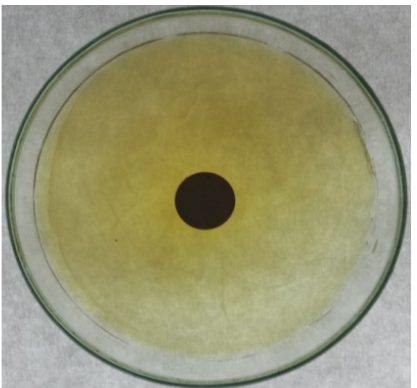

b) the Hap with $1 \% \mathrm{Zn}(\mathrm{SAE}) 2$

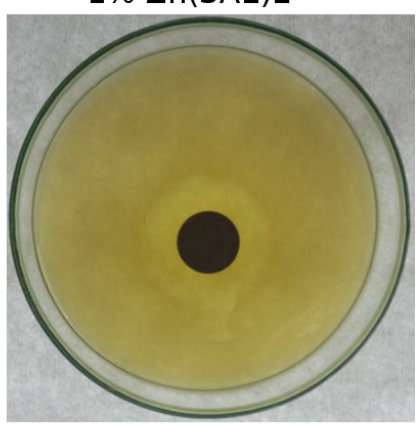

d) the Hap with $7 \% \mathrm{Zn}(\mathrm{SAE}) 2$
Fig. 6. Antibacterial tests using E-Coli bacteria of HAp compacts with various amounts of $\mathrm{Zn}(\mathrm{SAE}) 2$ additive.

\section{Conclusion}

The present work is based on the fabrication of HAp powder having antibacterial and anelgesic properties via Schiff base metal complexes (Zn(SAE)2). Pure and thermally stable hydroxyapatite powder was extracted from bovine bone by the thermal method. The phase purity and crystallinity of hydroxyapatite powder was determined by XRD analysis. The presence of Schiff base complex was verified using FTIR and EDS analyses. Antibacterial testing results showed that HAp powder with $\mathrm{Zn}(\mathrm{SAE}) 2$ has high bioactivity in comparison with pure HAp powder. The best result versus Escherichia Coli bacteria, in terms of antibacterial effect, was obtained with $0.7 \mathrm{~g} \mathrm{Zn}(\mathrm{SAE}) 2$. Thus, the author expects that the HAp ceramics with biologically modified features will be replaced with the present coating materials in implant and bone fillers applications in human body.

\section{Acknowledgments}

This study was financially supported by Sakarya University Commissions for Scientific Research Projects within the context of "BAP-2012-09-08-004" numbered project.

\section{References}

[1] S.J. Kalita, A. Bhardwaj, H.A. Bhatt, Mater. Sci. Eng. C 27, 441 (2007).

[2] L.L. Hench, J. Am. Ceram. Soc. 81, 1705 (1998).

[3] S. Yunoki, H. Sugiura, T. Ikoma, E. Kondo, K. Yasuda, J. Tanaka, Biomed. Mater. 6, 015012 (2011).

[4] L.L. Hench, J. Am. Ceram. Soc. 74, 1487 (1991).

[5] C.T. Kwok, P.K. Wong, F.T. Cheng, H.C. Man, Appl. Surf. Sci. 225, 6736 (2009).

[6] A.M.N. Barakat, M.S. Khill, A.M. Omran, F.A. Sheikh, H.Y. Kim, J. Mater. Process. Tech. 209, 3408 (2009).

[7] M.S.M. Ali, M. Jesmin, M.A.K. Azad, M.K. Islam, R. Zahan, Asian Pac. J. Tropical Biomed. 2, 1036 (2012).

[8] A. Majumder, G.M. Rosair, A. Mallick, N. Chattopadhyyay, S. Mitra, Polyhedron 25, 1753 (2006).

[9] A. Kajal, S. Bala, S. Kamboj, N. Sharma, V. Saini, Journal of Catalysts 2013, 893512 (2013).

[10] B. Cvek, V. Milacic, J. Taraba, Q.P. Dou, J. Med. Chem. 51, 6256 (2008).

[11] X. Qian, Z.Y. Ma, C.Z. Xie, F. Xue, Y.W. Zhang, J.Y. Xu, Z.Y.Qiang, J.S. Lou, G.J. Chen, S.P. Yan, J. Inorg. Biochem. 105, 728 (2011).

[12] R.P. Chinnasamy, R. Sundararagan, S. Govindaraj, JAPTR 1, 342 (2010).

[13] B.O. Ibrahim, M.A. Mohamed, M.S. Refat, J. Mol. Struct. 1056-1057, 13 (2014). 